\title{
"Lembrança eu tenho da Saracura": notas sobre a população negra e as reconfigurações urbanas no bairro do Bexiga
}

Larissa Nascimento ${ }^{1}$

\section{Resumo}

Localizado na região central da cidade de São Paulo, o bairro Bela Vista, popularmente denominado Bexiga, apresenta em sua gênese o quilombo urbano Saracura. No final do século XIX, com o patrocínio do governo brasileiro, italianos, principalmente calabreses, passaram também a fazer parte do referido cenário. Apesar da presença e protagonismo da população negra até os dias de hoje neste contexto, diferentes meios difundem a imagem do Bexiga como um bairro genuinamente italiano. Além disso, constantemente, o bairro tem sido alvo de intensos processos de redefinição territorial, o que tem promovido o deslocamento de famílias negras economicamente desfavorecidas. Diante das relações assimétricas que se constituíram, o presente artigo busca discutir as reconfigurações urbanas no bairro por um viés que considera o estudo das identidades e relações raciais como imprescindíveis para a compreensão do urbano. Desse modo, são feitas referências aos estudos de Lucena (1984), Rolnik (1989), Borges (2001), Castro (2006) e Oliveira (2008), no intuito de estabelecer um diálogo entre pesquisadores da sociologia urbana e da sociologia das relações raciais. Além de pesquisa bibliográfica, o estudo envolveu pesquisa audiovisual, entrevistas e observação participante.

Palavras-chave: Negro; Identidade; Memória; Sociologia Urbana; Bexiga.

\begin{abstract}
The Bela Vista neighborhood, located in the central region of São Paulo, popularly called Bexiga, has its genesis in the urban quilombo Saracura. In the late nineteenth century, under the sponsored of the Brazilian government, Italians, mainly Calabrians, also became part of that scenario. Despite the presence and protagonism of the black population until the present day in this context, the media disseminates the image of the Bexiga as a genuinely Italian neighborhood. In addition, constantly, the neighborhood has been the subject of intense territorial redefinition process, which has promoted the displacement of economically
\end{abstract}


disadvantaged black families. In the face of these asymmetrical relationships that formed, this article discusses the urban reconfigurations in the neighborhood considering the study of identities and race relations as essentials for understanding the urban. Thus, are made references to studies of Lucena (1984), Rolnik (1989), Borges (2001), Castro (2006) and Oliveira (2008). Besides bibliographic research, the study involved audio-visual research, interviews and participant observation.

Keywords: Black; Identity; Memory; Urban Sociology; Bexiga.

Recebido em: Agosto, 2013

Aceito em: Junho, 2015

Para citar este artigo:

NASCIMENTO, LARISSA; "Lembrança eu tenho da Saracura": Notas sobre a população negra e as reconfigurações urbanas no bairro do Bexiga. In: Revista Intratextos, 2014, vol 6, no1, p. 25-50. DOI: http://dx.doi.org/10.12957/intratextos.2014.7099 


\section{Introdução ${ }^{1}$}

O presente artigo discorre principalmente sobre as relações demarcadas em um bairro de São Paulo, a Bela Vista. Este bairro, popularmente conhecido como Bexiga ${ }^{2}$, está localizado na região central da cidade, mais precisamente ao sudoeste da Subprefeitura da Sé. Bexiga refere-se também a uma subdivisão não oficial do bairro, abrangendo os arredores da Rua Treze de $\mathrm{Maio}^{3}$, entre a Praça Dom Orione e a Rua Santo Antônio. Todavia, neste artigo a denominação Bexiga será predominantemente utilizada como sinônimo de Bela Vista. A Figura I a seguir retrata o mapa deste distrito e subdivisões.

\section{FIGURA1. Mapa: Distrito da Bela Vista}

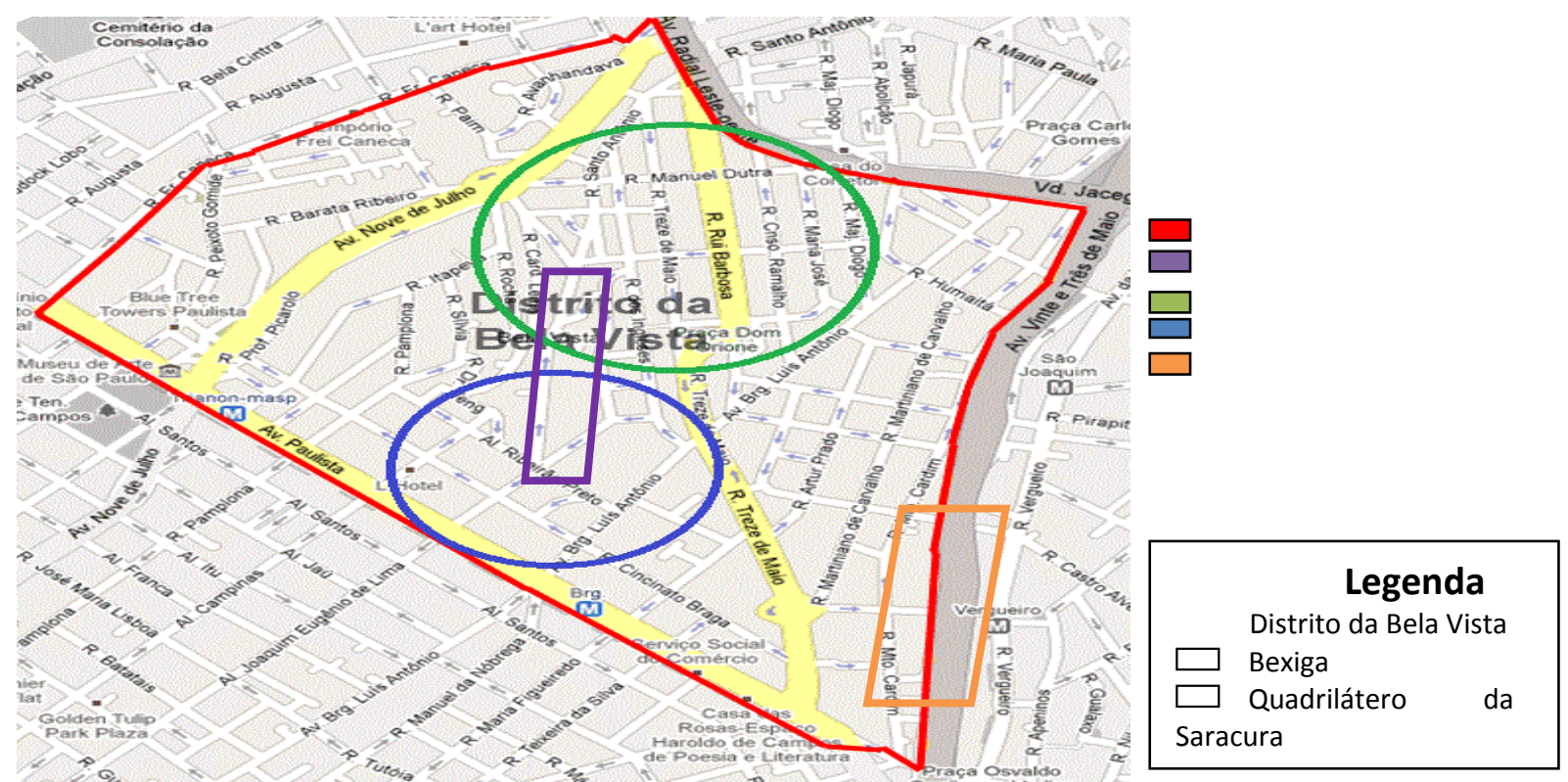

Fonte: NASCIMENTO, Larissa Aparecida Camargo do; 2013.

\footnotetext{
${ }^{1}$ Este artigo é um recorte de pesquisa de mestrado que versa sobre cultura e identidades no bairro da Bela Vista, com financiamento da CAPES.

${ }^{2}$ Em 16 de dezembro de 1910 foi promulgada a lei $n^{\circ} 1242$ que atribuiu à área o nome oficial Bela Vista. Castro (2006) aponta que é comum encontrar duas grafias em diversas fontes que tratam sobre a região: Bixiga e Bexiga. Bexiga seria a forma mais antiga e remete às origens do nome popular do bairro, Bixiga seria a denominação que teve origem no sotaque dos imigrantes italianos. Segundo Soares (1999), Bixiga - com 'i'- foi popularizado por meio das canções de Adoniran Barbosa e representaria uma tentativa da ala tradicional do bairro em resgatar um italianismo que se perdera. Apoiando-se na pesquisa de Francisco C. Scarlato - "O Real $e$ o Imaginário no Bexiga”, Tese de doutorado, FFLCH - USP, 1988 - Soares (1999) afirma que a ideologia do Bixiga também é usada pelos "donos de estabelecimentos comerciais, que pretendem, através da atração causada pelo exotismo de um bairro que seria 'um pedaço da Itália' em São Paulo, ampliar os seus lucros" (SOARES, 1999, p.17). Desse modo, nesse trabalho, preferencialmente, será utilizado o termo Bexiga.

${ }^{3}$ Segundo Sacchetto (2001) no começo do século XX os negros passaram a comemorar o dia 13 de maio (data em que foi assinada a Lei Áurea) nesta rua, era a Festa de Santa Cruz. Portanto, em 1916, a localidade que antes era Rua Celeste, passou a ser denominada Treze de Maio.
} 
O Morro dos Ingleses também é uma subdivisão não oficial do bairro. Próximo à Avenida Paulista, constituí uma das regiões mais valorizadas deste contexto. Já o Quadrilátero da Saracura significou um território habitado majoritariamente por negros. Delimitado pelas ruas Rocha, Una, Almirante Marques Leão e Avenida Nove de Julho, seu centro abriga a sede da tradicional escola de samba do bairro, o Grêmio Recreativo Cultural Social Escola de Samba Vai-Vai (GRCSES Vai-Vai). Obviamente a população negra do Bexiga extrapolou esses limites, residindo nos diversos cortiços espalhados pelo bairro. A Vila Itororó, localizada entre as ruas Martiniano de Carvalho, Monsenhor Passalacqua, Maestro Cardim e Pedroso, foi construída por um tecelão português entre os anos de 1916 e 1922. É uma das áreas mais antigas da cidade, constituída por um casarão e 37 casas repletas de adornos remanescentes da demolição do Teatro São José, primeiro teatro da cidade que fora destruído por um incêndio. Ao longo do tempo, esse conjunto arquitetônico transformou-se em cortiço. Tanto o contexto do Quadrilátero da Saracura como da Vila Itororó serão aprofundados na segunda seção deste estudo.

Delimitada por importantes avenidas do cartão postal de São Paulo, como a Avenida Paulista (coração econômico do país), Radial Leste e Vinte e Três de Maio, a Bela Vista é sem dúvida um distrito de grandes contrastes. Traçada tanto por modernos arranhacéus como por centenários casarões, muitos dos quais hoje não são mais as luxuosas residências, mas sim os cortiços onde reside um grande número de famílias por $\mathrm{m}^{2}$, o bairro abrange uma população diversa, tanto em termos de ascendência como em termos socioeconômicos, ainda que sua localização privilegiada, abarcando hospitais, postos de saúde, estações de metrô, escolas, museus, centros culturais, entre outros equipamentos de lazer, encareça cada vez mais os imóveis desta localidade.

Desse modo, pretende-se realizar uma reflexão acerca do significante racial dos sujeitos que compõem o bairro, por meio de um diálogo entre autores da sociologia urbana e pesquisadores importantes para a sociologia das relações raciais. Considera-se que a sociologia urbana é uma disciplina que se intersecciona com outras áreas do conhecimento como a geografia, urbanismo, antropologia, entre outras. Nesse sentido, a sociologia das relações raciais também apresenta grande relevância para a compreensão espacial da cidade, 
tendo em vista que o processo de racialização ${ }^{4}$ dos sujeitos negros reflete na marginalização desse grupo social e, consequentemente, no modo como o espaço urbano será ocupado.

No Brasil, apesar de não haver uma política oficial de segregação racial, há uma segregação que paira no plano invisível escamoteada por um falso discurso de democracia racial. De acordo com Campos (2012), uma sociedade que constitui suas relações por meio do racismo tem sua geografia, lugares e espaços com as marcas dessa distinção social. Assim o autor utiliza como exemplo o fato de no caso brasileiro a população negra ser majoritária nos presídios e absolutamente minoritária nas universidades. Pesquisadores como Guimarães (1999), Silvério (2002) e Paixão et al. (2010), sensíveis às desigualdades ocasionadas pela discriminação racial, denunciam uma sociedade racista e discorrem sobre como a população negra é excluída de direitos básicos como moradia, alimentação, saúde e educação, apontando a importância e urgência de políticas públicas voltadas para esse grupo social.

Castro (2006) revela que nos dias de hoje, apesar de apresentar um considerável número de moradores negros e nordestinos, a Bela Vista é representada como um bairro italiano da metrópole de São Paulo e que meios midiáticos como jornais impressos e programas televisivos possuem papel importante na divulgação dessa imagem. E apesar da literatura verificar a presença de negros antes mesmo da chegada dos imigrantes, representando um aspecto importante em relação à demografia da região, seu protagonismo na constituição da Bela Vista é pouco aprofundado, consequentemente há uma desvalorização dos aspectos culturais de matriz afro-brasileira. Ao aprofundarmos a leitura do trabalho de Lucena (1984), a impressão que se tem é que a ocupação efetiva da região só é considerada após a chegada dos imigrantes italianos.

Comumente referenciado por suas cantinas, padarias, arquitetura, teatros e inclusive pela tradicional festa italiana em homenagem a Nossa Senhora da Achiropita - hoje na sua $87^{\mathrm{a}}$ edição - o legado histórico, social e cultural afro-brasileiro do Bexiga não é exaltado da mesma maneira. Não se pretende aqui hierarquizar, (bi)polarizar as contribuições de negros e italianos, pelo contrário, ambos marcam forte presença no contexto do bairro e da cidade. Portanto, há pelo menos dois aspectos culturais diferentes e relevantes relacionados.

\footnotetext{
4 “Racialização ou 'formação de raças' se baseia no argumento de que raça é uma construção social e categoria não universal ou essencial da biologia. Raças não existem fora da representação. Em vez disso, elas são formadas na e pela simbolização em processo de luta pelo poder social e político. O conceito de racialização refere-se aos casos em que as relações sociais entre as pessoas foram estruturadas pela significação de características biológicas humanas, de tal modo a definir e construir coletividades sociais diferenciadas" (SILVERIO; TRINIDAD, 2012, p. 910).
} 
Ecosteguy (2006) nos chama a atenção para o fato de que não existe um confronto bipolar rígido entre diferentes culturas. Na prática, o que ocorre é um sutil jogo de intercâmbio entre elas. Assim, estas culturas não devem ser vistas como exteriores entre elas, mas comportando cruzamentos, transações, intersecções, negociações. Todavia é enganoso adotar a perspectiva de que os diferentes grupos identitários se hibridizam sem tensões, posto que estão situados assimetricamente em relação ao poder.

Considera-se que o momento particular da história do negro na Bela Vista e a história do negro na cidade de São Paulo entrelaçam-se, são complementares. Desse modo, entende-se que analisar os elementos da cultura afro-brasileira que estão latentes no Bexiga (CASTRO, 2006) significa uma medida que busca reconhecer parte significativa da história e das contribuições da população negra na cidade, bem como compreender o quanto e como suas manifestações são representativas da matriz afro-brasileira. Ademais, analisar as identidades dos sujeitos autodeclarados negros e as relações raciais pode oferecer contribuições para compreender tais fenômenos num sentido mais amplo, num contexto diferente do Bexiga. Em suma, deve-se reconhecer que as relações sociais são hierarquizadas uma vez que sujeitos não brancos são posicionados inferiormente, ou seja, diferenças fenotípicas e culturais são transformadas em desigualdade social.

O artigo foi estruturado em três seções, além desta introdução e considerações finais. Na primeira seção - Desde o Saracura - será apresentadauma contextualização do bairro, indicando em tese os principais atores de sua gênese. Tal contextualização representa uma pesquisa exploratória realizada a partir de um levantamento bibliográfico desde suas origens, até a sua atual configuração. Entende-se pesquisa exploratória como um estudo preliminar do campo que pode auxiliar na formulação da questão de pesquisa e elencar os principais objetivos. Parte-se da premissa de que a partir da história podemos entender as relações atuais e cotidianas mantidas nos espaços de investigação.

Na seção - Entre Cortiços e Desapropriações: Vila Itororó e Vai-Vai - pretendese discutir questões como desapropriações, o deslocamento de famílias negras do bairro, as assimetrias entre negros e brancos e a presença de outros grupos identitários no bairro. Além da bibliografia selecionada, foram utilizadas reportagens, documentários e também depoimentos de moradores ou ex-moradores negros cuja história de vida está de certa maneira vinculada à Escola de Samba Vai-Vai. Estes colaboradores são: (i) Joana, 56 anos, Coordenadora da Ala das Baianas, há 28 anos moradora do bairro; (ii) Paulo Rogério, 33 
anos, nascido no bairro, membro da Bateria da Vai-Vai; (iii) Carlos Alberto, o 'Pastel', 56 anos, nascido no Bexiga, desde criança ritmista na Bateria da Vai-Vai, encerrando sua participação em 2011. Seu pai fora presidente da Vai-Vai - o saudoso sambista José Jambo Filho - mais conhecido como Seu Chiclé; (iv) Fernando Borges Penteado, nascido no Bexiga, 66 anos, Diretor Geral de Harmonia. Seu pai - Frederico Penteado - foi um dos fundadores da Vai-Vai e, portanto, desde tenra idade participou da escola.

Na seção - Memórias e Vivências: As perspectivas de dois moradores negros - são apresentadas de uma maneira mais aprofundada duas entrevistas acerca da representação negra e italiana no bairro. Os sujeitos são um senhor e uma senhora que vivem neste contexto há mais de trinta anos, ambos não são militantes negros e também não participam de qualquer associação negra.

A metodologia utilizada durante as entrevistas foi a história de vida. Queiroz (1998) coloca a história de vida no quadro amplo da história oral e a considera uma ferramenta importante por se colocar justamente no ponto onde se cruzam vida individual e contexto social. Dessa maneira, a técnica da história de vida possibilita apreender as intersecções entre a identidade dos sujeitos negros e o contexto urbano em questão. Tais relatos foram captados por meio de entrevistas semiestruturadas. Conforme Queiroz (1998) as entrevistas semiestruturadas consistem em uma conversa entre entrevistado e pesquisador, conduzida por este último com vistas a atender os objetivos propostos pela investigação. A pesquisa utilizouse também da observação participante, frequentando os espaços, interagindo e conhecendo as pessoas no domínio de pesquisa.

\section{Desde o Saracura}

A resistência às relações de poder mantidas por sujeitos africanos e seus descendentes no período escravocrata do Brasil assumiu diferentes formas, da resistência cultural e religiosa à insubmissão aos trabalhos forçados, ocupação das terras disponíveis, revoltas, fugas, abandono das fazendas, formação de quilombos, entre outras estratégias (MUNANGA, GOMES, 2004).

Nas cidades, havia os chamados quilombos urbanos, ademais, a cidade oferecia uma chance maior de anonimato para os foragidos das fazendas. Segundo Rolnik (1989), tais espaços eram cômodos e casas coletivas no centro da cidade ou núcleos semirrurais - bastante semelhantes ao que são as roças de periferia dos terreiros de candomblé nas cidades. Ainda de 
acordo com a autora (1989) o terreiro seria um elemento espacial fundamental na configuração dos territórios negros urbanos - são terreiros de samba, de candomblé, de jongo, enfim, espaços que permitem a manifestação de elementos culturais que os atravessam ao longo da história. Dessa maneira, no final do século XIX se constituiu o Quilombo do Saracura, na região brejeira às margens do Ribeirão Saracura ${ }^{5}$. Este importante quilombo urbano, segundo o estudo de Rolnik (1989), originou o bairro do Bexiga, localizado na região central de São Paulo.

Além da versão do Quilombo do Saracura preceder o bairro, autores como Lucena (1984), Borges (2001), Sacchetto (2001)eCastro (2006) apresentam a existência de outras versões sobre sua origem a partir da sua nomeação popular Bexiga. Esse fato não só é curioso, mas pode revelar que há por trás uma disputa entre grupos distintos acerca de quem seriam os pioneiros nessa localidade. De acordo com uma das referidas versões havia uma hospedaria próximo ao Largo do Piques ${ }^{6}$ cujo dono chamava-se Antonio Bexiga. Bexiga seria um nome popular que faz referências à doença varíola, portanto, um apelido, uma vez que Antonio apresentava as marcas da doença no rosto. Outra versão considera que pelo fato da Bela Vista encontrar-se, na época, numa região mais afastada do núcleo urbano, seria um lugar que acolhia escravizados acometidos pela mesma doença, como maneira de isolar os doentes. Uma terceira hipótese menciona que a denominação teria origem no fato de o dono da chácara comercializar "bexiga de boi", negócio lucrativo e bastante explorado na São Paulo daquela época.

Segundo os autores citados acima e mesmo no documentário Memória em Pedaços: Bairro do Bixiga (DUARTE; POSILI, 1997), a baixada do Largo do Piques, atualmente Praça da Bandeira, era um local onde ocorria uma vez por semana o leilão de escravizados. Fugas também faziam parte desse cenário:

\footnotetext{
As capoeiras e capinzais que havia em torno do Tanque Reúno, no Bexiga, como em outros pontos que corriam o Anhangabaú e o Riacho do Saracura, serviram de esconderijo onde se aquilombavam negros rebelados. Esses matos eram convidativos para esconderijos. Em 1831 foi feito um documento com a tentativa de
}

\footnotetext{
${ }^{5}$ O Ribeirão Saracura possui sua nascente na região da Avenida Paulista, atualmente canalizado por galerias subterrâneas, ele desce a Rua Rocha até a Avenida Nove de Julho, onde segue até desaguar no Ribeirão Anhangabaú.

${ }^{6}$ Atualmente é o Largo da Memória próximo ao metrô Anhangabaú.
} 
fechar o acesso do Anhangabaú para o Bexiga, cujo objetivo era impedir o trânsito de escravos fugitivos para o Bexiga (LUCENA, 1984, p.24).

Observa-se ainda que Lucena (1984), Borges (2001) e Castro (2006), entre outros pesquisadores, utilizam a citação de Afonso A. de Freitas que anuncia lá pela década de 1870, antes da ocupação em massa de imigrantes italianos, que "a Chácara do Bexiga possuía extensas plantações de jabuticabeiras, laranjeiras e capinzais, onde se caçavam veados, perdizes e até escravos fugitivos”. Portanto, revela-se que escravizados foragidos desde muito antes habitavam os campos do Bexiga, constatação que concorda de certa maneira com o artigo de Raquel Rolnik (1989).

Logo após a Abolição da Escravatura, a cidade de São Paulo passou por uma intensa redefinição territorial/racial, encabeçada pelo poder público e pela elite paulistana, fazendo com que os negros se deslocassem para as regiões mais periféricas da cidade. A "limpeza" do Centro Velho ocorreu durante a gestão do prefeito Antônio Prado (1899 - 1911) e caracterizou-se pelo desalojamento da população negra que ali vivia. Diante do desalojamento forçado, uma parcela considerável de negros se deslocou para o Bexiga tendo em vista o já existente núcleo negro do Saracura e a proximidade em relação às regiões valorizadas da cidade - como Avenida Paulista, Rua Consolação, Rua Brigadeiro Luis Antônio e arredores que demandavam mão de obra braçal, principalmente nas mansões dos barões do café, fatores que contribuíram para que, na época, o Bexiga se consolidasse como um importante território negro da zona central da cidade. Koguruma (2001) apud Castro (2008, p.54) destaca no jornal Correio Paulistano de 03 de outubro de 1907 uma descrição da região do Saracura enfatizando sua população predominantemente negra:

[A Saracura] É um pedaço da África. As relíquias da pobre raça impellida pela civilização cosmopolita que invadiu a cidade, ao depois de 88 , foi dar ali naquela furna.

$\mathrm{O}$ vale é fundo e estreito. Poças dagua esverdeada marcam os logares donde sahiu a argila transformada em palacetes e residências de luxo.

Cabras soltas na estrada, pretinhos semi-nus fazendo gaiolas, chibarros de longa barba ao pé dos velhos de carapinha embranquecida e lábio grosso de que pende o cachimbo, dão áquelle recanto uns ares do Congo (KOGURUMA, 2001, p.210 apud CASTRO, 2006, p. 57). 
Todavia, no Pós-Abolição, não foram tomadas medidas para garantir a inserção, proteção e sobrevivência dos negros. Segundo Hofbauer (2003) a elite brasileira queria mudanças econômicas, mas ao mesmo tempo preocupava-se em manter a velha estrutura de poder. Portanto, concomitantemente à exclusão geográfica da população negra, houve a exclusão racial do trabalho, restando aos negros os trabalhos mais penosos e mal remunerados. Assim, as oportunidades foram monopolizadas pelas antigas camadas dominantes e pelos imigrantes europeus. Teorias racistas impulsionaram o governo a patrocinar a vinda massiva destes imigrantes para substituir a mão de obra dos escravizados recém "libertos", pois defendia-se que o progresso do país ocorreria a partir do branqueamento da população, o que impunha o "branqueamento fenotípico" por meio da miscigenação, com o intuito de supressão da população negra. Nesse sentido, no final da década de 1870, atraídos pelos baixos preços, italianos, principalmente calabreses ${ }^{7}$, ocuparam o Bexiga. Desse modo, no Bexiga do século XX não havia senzalas, mas sim porões dos casarões e cortiços, cujos principais inquilinos eram negros. Essa seria uma das particularidades do racismo à brasileira, onde as pessoas convivem juntas, porémsão segregadas; onde ao mesmo tempo em que a miscigenação é celebrada, sujeitos são constantemente discriminados racialmente.

\section{Entre Cortiços e Desapropriações: Vila Itororó e Vai-Vai}

[...] Lembrança eu tenho da Saracura

Saudade tenho do nosso cordão.

Bexiga hoje é só arranha-céu e não se vê mais a luz da Lua. Mas o Vai-Vai está firme no pedaço.

É tradição e o samba continua FILME, Geraldo.Tradição. 1980.

Frente ao processo de racialização, sujeitos negros organizaram-se na perspectiva de obterem melhores condições de vida e reconhecimento, objetivando quebrar preconceitos e

\footnotetext{
${ }^{7}$ Segundo Castro (2006) o fenômeno do Estado italiano, enquanto unidade federativa era algo extremamente recente nos idos de 1880. As questões regionalistas, muito vivas ainda hoje naquele país, enfatizavam as particularidades dos diversos grupos oriundos da Península Itálica
} 
atingir a igualdade social, e, para tanto, formaram associações políticas e culturais. A partir das primeiras décadas do século XX, algumas dessas instituições originaram a Imprensa Negra, Escolas de Samba, Clubes Sociais Negros, a Frente Negra Brasileira (1930), o Teatro Experimental do Negro (1944), o Movimento Negro Unificado na década de 70, entre outros. Em São Paulo, enfatizando brevemente esse protagonismo negro na Bela Vista, podemos destacar a fundação do jornal O Clarin D’Álvorada (1928) e do cordão carnavalesco Fio de Ouro (1963) - atualmente inativos - e a criação do grupo carnavalesco Cai-Cai, hoje escola de samba GRCSES Vai-Vai (1928). E, mais recentemente, é possível mencionar a fundação da Pastoral Afro Achiropita (1988) e do terreiro de candomblé Instituto Afro Religioso Ilê Asé Iyá Ossun (1980). Tanto a Pastoral, o Ilê e o GRCSES Vai-Vai - única escola de samba ativa no centro da capital paulista - são muito presentes no cotidiano do bairro, mesmo com o constante deslocamento de famílias negras.

Fernando Penteado, único depoente desse estudo que atualmente não reside mais no bairro, ao discorrer sobre a sua identificação com a Bela Vista, a Saracura e a Vai-Vai, explicita a divisão racial do território de tempos atrás:

Nasci na Saracura. Ali era um brejo. Tem um rio que passa por baixo. Ele passa ali onde hoje a Vai-Vai ensaia, passa na Nove de Julho e deságua no Viaduto do Chá. Toda a água da Avenida Paulista desencana ali (região da Vai-Vai), ali era um brejo e ninguém queria morar lá. Então, os italianos ficavam na Rua Rocha (mais acima) e a gente ficava embaixo. Isso lá atrás, né. Os negros ficavam todos aqui embaixo. E quando falava de Saracura era pejorativo, mas nós assimilamos o apelido. Então falamos no samba: 'É o Vai-Vai do Bexiga, Orgulho da Saracura'. Hoje nosso puxador, ele grita "Alô Saracura". (...). Eu sou do Saracura, sou da Bela Vista, sou do Bexiga, essa interação é muito forte. Hoje não moro mais no Bexiga, mas se quiser se esconder de mim é me procurar em casa. Porque eu fico mais pra cá (Bela Vista) (PENTEADO. Entrevista realizada em 22/07/2013).

De acordo com o IBGE (2010) a Bela Vista possui aproximadamente 69.460 habitantes; com uma área de $2,6 \mathrm{Km}^{2}$ representa o distrito mais populoso da cidade de São Paulo, com uma densidade demográfica de 26,715(Hab/ $\left.\mathrm{Km}^{2}\right)$. Segundo a $\mathrm{HABI}^{8}$ cerca de

8 Prefeitura do Município de São Paulo, HABI - Superintendência de Habitação Popular. Cortiços: A Experiência de São Paulo, 2010. Disponível em: <http://www.habisp.inf.br/theke/documentos /publicacoes/corticos/index.html>. Acesso em: 25 jan. 2013. 
3.460 famílias estão distribuídas entre os 267 cortiços do Bexiga. Os cortiços, antigos casarões cujo interior é subdividido de modo a comportar um grande número de famílias, onde até os porões são habitáveis, é característico do bairro desde a imigração italiana, no final do século XIX. Todavia, ao aprofundarmos o estudo da bibliografia, a pesquisa de campo e o diálogo com os moradores desse contexto, constatou-se que os principais moradores destes cortiços eram negros, e não os migrantes italianos. Ao relembrar sua mocidade no bairro, Penteado relata: "quem morava nos cortiços eram os negros. Os italianos moravam em sobrados" (PENTEADO. Entrevista realizada em 22/07/2013). Pastel, por sua vez, também relembra: "Nos cortiços, você percebia mais era a presença das pessoas da pele preta mesmo" (PASTEL. Entrevista realizada em 25/07/2013).

Por se encontrar em uma área atualmente valorizada, muitos cortiços do Bexiga foram derrubados para a construção de habitações verticalizadas voltadas aos setores favorecidos economicamente (OLIVEIRA, 2008), e assim, um grande número de moradores negros e pobres que habitavam o bairro tiveram que se deslocar para regiões periféricas da cidade, com custos mais baixos. Além disso, obras públicas, como a Ligação Leste-Oeste e o Elevado Costa e Silva, popularmente denominado Minhocão, também resultaram na mudança de antigos moradores:

Antigamente, a Bela vista era um bairro bastante negro. Eu lembro na minha infância. Muita coisa aconteceu, foi afastando, pelo fato da Bela Vista encarecer. É muito caro, hoje, morar na Bela Vista. E fato, a Bela Vista está espalhada por São Paulo toda. Na zona leste, na Cohab II (Itaquera), tem uma rua que é metade da Bela Vista morando lá. Muita gente na zona sul, Campo Limpo, lembro que a minha mãe ia morar lá também. Na Casa Verde tem bastante gente também. A Vai-Vai deixou de ser negra por conta do alto valor imobiliário. (...) Grande parte da Bela Vista hoje é nordestina (PAULO. Entrevista realizada em 08/07/2013).

Nessa época (na minha juventude) tinha muito negro no Bexiga. Era muito mais unido o negócio. A negritude era forte. Hoje em dia não se tem mais. (...). Esse fim teve começo quando começaram a mandar o pessoal pra Cidade Tiradentes, para aqueles lugares todos, isso foi se perdendo. (...). Começaram a ver que o Bexiga era um bairro centralizado e precisava de uma nova cara, e para colocar essa nova cara precisava desalojar um monte de pessoas. 'E onde vamos mandar essa galera?' Vamos mandar para as periferias, tipo Itaquera, São Miguel, Vila Formosa. Aí esses lugares foram ficando saturados e então criaram a Cidade Tiradentes. Muita gente que eu conheci foi pra lá, muita gente acabou indo pra Cidade Tiradentes. (...). 


\begin{abstract}
Alguns receberam casa, prédios do CDHU, não tiraram o pessoal de qualquer maneira. Quem tinha melhor condição, ia pra Vila Mariana, Santana. Eu era novo, como tinha minhas amizades por aqui, quis ficar aqui. Era uma época que estavam construindo metrô, a Praça Roosevelt (PASTEL. Entrevista realizada em 25/07/2013).
\end{abstract}

Carlos 'Pastel' menciona a Cidade Tiradentes como um dos principais destinos das famílias negras, tendo em vista os planos de moradia ofertados na época, face aos altos custos da moradia na região central. Localizada na zona leste de São Paulo, a Cidade Tiradentes abriga o maior complexo de conjuntos habitacionais da América Latina, fora planejada e construída pelo poder público Municipal $(\mathrm{COHAB})^{9}$ e Estadual $(\mathrm{CDHU})^{10}$ na década de 80, destinado à famílias atingidas por obras públicas (SÃO PAULO, s/d). Sendo assim, os dados da Coordenadoria Regional de Saúde (CRS), Supervisão Técnica de Saúde (STS) e Distrito Administrativo (DA), apontam que a Cidade Tiradentes é o terceiro maior distrito de São Paulo em termos de proporção de moradores negros $(56,1 \%)$ - significando 118.586 habitantes. Já a população negra da Bela Vista representa 21,7\%, o equivalente a 15.036 habitantes.

Atualmente os cortiços da Bela Vista são habitados principalmente pela população nordestina, ademais tanto os depoimentos como a vivência no bairro têm apontado a existência de um número considerável de moradores provenientes do continente africano, entre eles senegaleses e nigerianos. Todavia, os projetos urbanos que culminam no deslocamento de determinados setores da população para bairros periféricos são um processo sem data de fim, pelo menos no Bexiga. O estudo de D’Alambert e Fernandes (2006) permite constatar o interesse de grupos distintos em "requalificar" a região da Bela Vista, com a intenção de fortalecer seu caráter turístico e cultural. Nesse sentido o bairro é objeto de planos de revitalização e consequente valorização de imóveis.

Desde 2002, uma série de imóveis da Bela Vista foram tombados de acordo com a resolução n²2/2002 do CONPRESP (Conselho Municipal de Preservação do Patrimônio Histórico, Cultural e Ambiental da Cidade de São Paulo). Entretanto, D’Lambert e Fernandes (2006) consideram que a ação não foi capaz de reverter a situação "decadente" em que o bairro se encontra:

\footnotetext{
${ }^{9}$ Companhia Metropolitana de Habitação de São Paulo.

${ }^{10}$ Companhia de Desenvolvimento Habitacional e Urbano do Estado de São Paulo.
} 


\begin{abstract}
Como outros bairros paulistanos situados na área central, a Bela Vista apresenta-se no momento bastante deteriorada urbanisticamente devido principalmente ao grande número de velhas residências decadentes transformadas em cortiços, a falta de áreas verdes e de espaços de lazer e recreação, ao sistema viário inadequado e à falta de infraestrutura urbana para instalação de novas atividades comerciais e de serviços (estacionamentos, metrô, etc.). O bairro se encontra praticamente estagnado, necessitando de grandes estímulos financeiros de ordem institucional e privada para promover a sua revitalização [...] (D’ALAMBERT; FERNANDES, p.155, 2006).
\end{abstract}

Nesse sentido, em março de 2013 as últimas famílias que residiam na Vila Itororó, antigo cortiço do bairro, foram desapropriadas. Em 2011, ano em que as primeiras famílias foram removidas, a Vila significava residência para 86 famílias (VEIGA; BUGARELLI, 2012). De acordo com Bevenuti (2013), em 2006, por meio de um decreto de utilidade pública, o governo do Estado de São Paulo desapropriou com uma indenização ao proprietário oficial, a Fundação Augusto de Oliveira Camargo. Em seguida o imóvel foi repassado para a Prefeitura de São Paulo, responsável por elaborar um plano de restauração. Considerando que seria inviável a permanência dos moradores depois da reforma, a Secretaria de Habitação (Sehab) ficou responsável pelo atendimento provisório das famílias e o CDHU em construir e financiar suas habitações.

O curta-metragem de Manfrini (2011), que contou com a participação de alguns moradores da Vila Itororó, apresenta o projeto de transformação do antigo conjunto arquitetônico em um polo cultural com repercussão internacional. Tal projeto foi motivo de grande insatisfação posto que a demanda emergencial da população local envolveria questões habitacionais e não a criação de um novo estabelecimento cultural. Um dos principais argumentos nesse sentido enfatiza que o Centro Cultural de São Paulo, instituição pública que reúne um conjunto de bibliotecas, espaços expositivos, teatro, cinema e cursos, estaria há apenas alguns metros de distância da referida localidade. Ademais, as reclamações envolviam o pagamento da indenização, que deveria ser destinada aos moradores que viviam há mais de cinco anos na localidade sem pagar aluguel. Alguns moravam lá há trinta anos. Outras revindicações diziam respeito às medidas provisórias e definitivas em relação à moradia: o valor integral da bolsa aluguel representaria uma quantia insuficiente para garantir a permanência dos moradores no bairro e havia trâmites burocráticos que dificultavam a 
concessão de um financiamento imobiliário pelo CDHU. Os moradores, portanto, eram favoráveis à restauração da Vila desde que garantido o direito de residi-la. Porém, o Sub Secretário de Cultura de São Paulo, José Roberto Sadek, discorre:

As pessoas não tinham poder aquisitivo, invadiram o local e foram morando. (...). Essa improvisação, essa necessidade de morar lá, gerou uma deterioração na arquitetura original. Não há um técnico consistente que fale que a gente deveria manter essa deterioração. Há uma unanimidade entre os pareceristas técnicos de que a gente deve restaurar a casa como ela era, e não como foi degenerada, ou foi deturpada, pelo uso obrigatório de uma residência (Entrevista concedida a MANFRINI, 2011).

Infelizmente, os relatos de despejo de famílias inteiras não é novidade na região com um dos $\mathrm{m}^{2}$ mais caros de São Paulo, onde um quarto pequeno e sem janela pode custar R\$ 300,00 por mês. Em entrevista, o escritor e pesquisador Márcio Castro (MAPA COLETIVO MAPA XILOGRÁFICO, 2009) associa a revitalização aos processos de especulação imobiliária e expulsão. Revela que em bairros centrais, como a Bela Vista, os sujeitos de baixa renda possuem acesso a uma boa infraestrutura, como escola pública, transporte, metrô, posto de saúde, centros culturais. No entanto, o processo de revitalização obriga o deslocamento para localidades onde o governo se faz presente principalmente por meio da violência, pela polícia.

Complementar ao atual processo de reconfiguração urbana e valorização dos imóveis está a construção da estação do Metrô Linha 6 - Laranja (São Joaquim - Brasilândia), que liga o bairro à zona norte da cidade. Oprojeto da Companhia Metropolitano de São Paulo prevê a desapropriação de imóveis residenciais e comerciais, e, portanto, o deslocamento de moradores. Entre as desapropriações, uma das mais polêmicas é a sede da Vai-Vai, há 85 anos compondo a história do bairro - dois anos comotime de futebol e grupo carnavalesco chamado Cai-Cai - 1928 e 1929; 42 anos comoCordão Carnavalesco e Esportivo Vae Vae e 41 anos como Grêmio Recreativo Cultural e Escola de Samba Vai-Vai.

Joana em seu depoimento refuta aqueles que difundem a imagem do Bexiga como um bairro unicamente italiano, evidenciando a participação da população negra na tradicional festa em homenagem a Nossa Senhora Achiropita. Além disso, sublinha a Vai-Vai como representação da população negra: 
Segundo D. Olímpia e o povo mais antigo, falam que a Vai-Vai, que na época era Cai-Cai, era ela que evoluía o povo aqui. Saia pelas ruas do bairro. Não é do meu tempo, mas eu acho que tinham que respeitar isso, e não falar só sobre o bairro italiano. Você vê que na festa da Achiropita é uma mistura, é negro, é italiano, é tudo. Não sei porque eles querem fazer essa diferença. Eu não entendo. Eu sinceramente não entendo (...). A gente tem tanta foto, temos um monte de gente, como o finado Branca de Neve, um monte de gente que conseguia empurrar com o Vai-Vai, e o Vai-Vai é aqui do Bexiga (JOANA. Entrevista realizada em 17/07/2013).

Notrecho há referências a duas personalidades negras: D. Olímpia e Branca di Neve. A primeira, cuja idade ultrapassa os noventa anos, fora responsável por mais de duas décadas da Corte do Cordão Carnavalesco, atualmente é Velha-Guarda da Vai-Vai, moradora do Bexiga até os dias de hoje. Já Branca di Neve seria o nome artístico de Nelson Fernando de Moraes, cantor e compositor de samba-rock, nascido no Bexiga. Branca di Neve morreu precocemente, no auge de sua carreira, e infelizmente, sua história e atuação no bairro não é devidamente difundida.

Na continuidade de sua fala, a Coordenadora das Baianas sugere que a saída da VaiVai não se deve apenas à estação de metrô, revelando a tensão com moradores residentes nos prédios próximos:

Como eu não entendo também esse povo que chegou outro dia. O povo dos prédios (da vizinhança da Vai-Vai) chegaram outro dia, e aí fazem abaixo assinado, xingam, põem na internet, eu não entendo. Quando chegaram aqui já tinha a Vai-Vai. Antes não tinha prédio, não tinha nada, tinha um rio aqui no meio. Como é que pode, né? (JOANA. Entrevista realizada em 17/07/2013).

Paulo, por sua vez, explicita que surgiu um movimento denominado Fica Vai-Vai no Bexiga, formado principalmente por moradores do bairro e membros da Vai-Vai. Segundo ele, essa mobilização ocorreu após uma preocupante reportagem que afirmava a mudança da Vai-Vai para o bairro da Luz, na região central pejorativamente denominada Cracolândia: 
que tinha lá. A região da Bela Vista tem a estação de metrô São Joaquim, Liberdade,Trianon e Brigadeiro. E eu não consigo entender o porquê fazer logo ali. Por que fazer ali, numa região que alaga? Chove e alaga tudo. Eu queria entender o porquê fazer um metrô aqui, sendo que na Avenida Paulista fizeram, e nenhuma banca de jornal foi desapropriada. Querem que o Vai-Vai revitalize a Cracolândia. Mas no próprio bairro tem muitos moradores de rua, onde era o Teatro Záccaro (na Rua Rui Barbosa), por exemplo. O próprio bairro necessita da Vai-Vai. (...). É complicado, a Vai-Vai tá bem na região da Avenida Paulista. E quem quer uma escola de samba perto da Paulista? Tem gente que diz que o samba é coisa de negro, coisa de maloqueiro (PAULO. Entrevista realizada em 08/07/2013).

Além da indignação em relação ao local da nova estação de metrô, seu depoimento caracteriza a Vai-Vai como um território predominantemente negro e, por isso, marginalizado e estigmatizado, inapropriado para estar nas proximidades do centro financeiro do país. Devese considerar ainda, que apesar de muitos membros da Vai-Vai estarem espalhados pelas periferias da cidade, fazem-se presentes no bairro nos momentos de festividade e mobilização da Escola.

\section{Memórias e vivências: As perspectivas de dois moradores negros}

Com o intuito de captar as dinâmicas raciais na Bela Vista para além das questões que envolvem a região da Saracura e da Vila Itororó, foram realizadas duas entrevistas com sujeitos autodeclarados negros, moradores na localidade e não militantes em associações negras. Atribuímos a eles os nomes fictícios de Célia e Benedito. Dona Célia é uma senhora negra de 72 anos, que nasceu em Minas Gerais, foi criada em Espírito Santo e reside na Bela Vista,segundo ela, há pelo menos trinta anos. Foi embora de Espírito Santo para São Paulo com o intuito de libertar-se das violências do ex-marido, levando consigo duas filhas ainda pequenas. Antes de mudar-se para a Bela Vista, residia em São Miguel Paulista. A mudança foi motivada pela oportunidade de trabalho:Dona Célia é cozinheira. A primeira residência no bairro foi em um quarto de pensão onde vivia com duas filhas e dois netos. O pequeno portão de ferro, onde estão pregadas duas plaquinhas com os seguintes dizeres: "Vende-se Tapioca e Salgados" e "Aluga-se vagas para rapazes", escondem um casarão antigo onde mora esta senhoraque afirma: 
Tenho aluguel, uma coisa e outra pra pagar. Então, eu coloquei umas camas aqui. Já que eu não estou fazendo mais nada (trabalhando fora de casa) e a casa é grande, coloquei umas camas e uns meninos para morar pra poder me dar uns dinheirinhos e ajudar a pagar aluguel, água e luz. [...] E aqui não é pensão, são apenas dois quartos, é uma casa de família. E eu pego no pé, não deixo entrar com bebida, se for drogado eu descubro logo e mando embora. Só alugo vaga, cada um que vem só traz roupa (CÉLIA. Entrevista realizada em 21/05/2012).

Neste trecho constatamos que alugar vagas não é um problema para Célia, pelo contrário, é uma estratégia, uma solução para sanar as dificuldades financeiras. Tanto ela como o Seu Benedito não utilizam a palavra cortiço, mas sim pensão, há ainda uma preocupação de Dona Célia em distinguir sua residência de uma pensão ou cortiço.

Quando questionada se a Bela Vista é um bairro italiano, Célia afirma que há poucos italianos agora, diz que onde há muito italiano é no bairro da Mooca. Afirma ainda:

A maioria dos rapazes que ocupam as camas de minha casa são nordestinos, dificilmente vem pessoas de outros lugares. São rapazes que trabalham por aqui nos restaurantes, mas restaurantes assim, tudo do nordeste, né? Tem 'pizzaiolo', cozinheiro, ajudante de cozinha... A maioria das cantinas italianas viraram restaurantes nordestinos. Aonde você via que vendia uma pizza, um macarrão, uma massa italiana, você vê que virou tudo bar nordestino. (...). Antes tinha muito italiano residindo no bairro, mas hoje você pode descer a Rua Treze de Maio e do lado direito verá apenas bares nordestinos. (...). A Rua Treze de Maio, ainda é uma rua boa, mas nem chega perto ao que era antes (CÉLIA. Entrevista realizada em 21/05/2012).

A última frase demonstra como as hierarquias não existem apenas entre brancos e negros. De certa maneira Célia desqualifica os bares nordestinos em relação aos comércios tradicionalmente italianos. Revela-se, portanto que os grupos sociais podem formar-se em torno dos mais diversos pressupostos, dentre os quais as condições étnico-racial, religiosa, regional, que de certa forma ultrapassam as determinações econômicas. Partindo desseprincípio o grupo social de nordestinos, formado a partir do pertencimento regional, está posicionado de maneira hierarquizada na estrutura social. Além disto, Caldeira (1984) aponta que os migrantes encontram-se, de um modo geral, numa situação de inferioridade no 
conjunto da população ocupada. Dessa maneira, famílias migrantes podem encontrar maiores dificuldades para garantir a subsistência.

Finalizando este diálogo, a senhora diz que o casarão é alugado, portanto ela subloca. O dono do imóvel é um senhor italiano, que reside na Rua dos Franceses em um prédio onde há um apartamento por andar, a quem o aluguel é pago diretamente. Ao relatar isto afirma que "bate o maior papo com o proprietário", um engenheiro que segundo ela "é um amor de pessoa. Não é como a imobiliária. Se atraso (o pagamento) ele entende. Então, vou depositando o dinheiro conforme posso diretamente na conta dele" (Célia. Entrevista realizada em 21/05/2012). De acordo com ela, o proprietário possui muitos escritórios alugados na região central. Uma vez contou a ela a história do casarão, que era do seu avô:

O avô dividiu (o terreno) e construiu casas, quando faleceu e as casas ficaram para os filhos. Os filhos foram vendendo, e depois veio ele que era neto, que ficou com esta parte aqui por perto. A parte dele quem continua é só ele, os irmãos venderam suas partes (CÉLIA. Entrevista realizada em 21/05/2012).

Percebe-se nesse trecho que a condição social do descendente de italiano é muito diferente da realidade damulher negra. Cabe ainda observar que Marco reside na Bela Vista, porém numa região próxima da Avenida Paulista, muito mais valorizada, na subdivisão não oficial do bairro conhecida como Morro dos Ingleses. No entanto, eles sentam juntos sob o mesmo teto e conversam, parecem inclusive possuir uma relação de amizade. Isto ocorre provavelmenteporque segundo Santos (2012) há na nossa sociedade um complexo padrão de relações raciais que mistura, no cotidiano das relações sociais, momentos onde há interações marcadas pela horizontalidade, integração e igualdade entre negros e brancos e, ao mesmo tempo, outros momentos onde há verticalidades, hierarquias e diferenças em que são transformadas em desvantagens ou vantagens desiguais entre esses grupos. No interior do casarão alugado por Célia há uma horizontalidade entre ambos, contudo, quando estes se deslocarem para outros espaços, há grandes possibilidades de haver diferença no modo como serão tratados.

Momentos de horizontalidade e verticalidade entre negros e brancos foram observados também nas falas de Seu Benedito, senhor de74 anos, pernambucano e residente na Bela Vista desde quando migrou para São Paulo, em 1968. Como dona Célia, também não possui casa 
própria. Ao todo já mudou quatro vezes para imóveis cujos donos eram italianos, todavia imobiliárias mediavam os pagamentos. Sendo assim, não houve relações de proximidade com os proprietários, entretanto, destaca que estes possuem bastante imóveis, os quais estão sempre reformando e alugando. Quando questionado se o Bexiga é um bairro italiano, responde: "Agora tá muito misturado, muito nordestino, né? E sempre teve negros aqui, os patrícios. Os patrícios seriam aqueles da minha cor" (BENEDITO. Entrevista realizada em 08/09/2012).

Ao perguntar se havia espaços onde se concentravam mais negros ou mais brancos morando respondeu: "A Rua Treze de Maio é um reduto italiano, assim como a Rua Rui Barbosa, Quatorze Bis e Barata Ribeiro. Já nos casarões há muitos nordestinos” (BENEDITO. Entrevista realizada em 08/09/2012). Quando questionado se estes nordestinos são brancos ou negros, responde: "Tem mais negros nos cortiços, tem muito paraibano e pernambucano" (BENEDITO. Entrevista realizada em 08/09/2012).

Benedito identifica ainda como espaços de sociabilidade negra a Escola de Samba Vai-Vai, o Paulistano da Glória e o Clube Social Negro Aristocrata, que frequentava nos anos 70 a 80 e, segundo ele, muito frequentado também por outros negros moradores do Bexiga. Uma última questão diz respeito à convivência entre descendentes de italianos e negros no bairro. Foi perguntado se o entrevistado já presenciou situações de discriminação:

\footnotetext{
Vejo uma convivência sem conflito, se dão muito bem, nunca presenciei uma situação entre os "patrícios", italianos e portugueses. Os italianos gostam muito dos pretos trabalhando na cozinha (BENEDITO. Entrevista realizada em 08/09/2012).
}

Essa fala de Benedito, paradoxalmente, ao mesmo tempo em que celebra a convivência harmoniosa, evidencia hierarquias sociais cristalizadas ao restringir o sujeito negro ao papel de empregado, ao espaço da cozinha. Tal depoimento vai ao encontro de um intrigante trecho contido no documentário Memórias em Pedaços: Bairro do Bexiga (DUARTE; POLI,1997). Na parte que nos interessa, a jornalista diz durante uma cena em que homens negros trabalham numa padaria tradicional do bairro: "O segredo da massa é italiana, mas quem a prepara todos os dias são mãos nordestinas. Uma mistura de raças que começou há muito tempo" (DUARTE; POLI, 1997). No mesmo documentário, um senhor italiano, proprietário desta tradicional padaria, acrescenta: “(...) a minha mulher... não pode ouvir. Eu 
tive por mais de vinte anos uma amante negra" (DUARTE; POLI, 1997). E a jornalista finaliza: "As histórias de amor no Bexiga são também histórias de descobertas. Negros e italianos se deixam seduzir pelo que o outro tem de melhor" (DUARTE; POLI, 1997).

O tom do discurso é próximo ao mito fundador das três raças. Houve a tentativa de representar uma suposta convivência harmoniosa entre negros, italianos e nordestinos na Bela Vista. Todavia a representação sexualizada da mulher negra ou a caracterização subordinada de negros e nordestinos, limitados ao espaço da cozinha, verificam as hierarquias raciais neste contexto.

\section{Considerações finais}

Mesmo com a dispersão da população negra da Bela Vista, tendo em vista as reconfigurações urbanas e os altos custos dos imóveis, os sujeitos entrevistados refutam as representações midiáticas do Bexiga enquanto um bairro genuinamente italiano. Apesar da tentativa de invisibilização, os negros estão presentes tanto na história como no cotidiano do bairro. E mesmo aqueles que são ex-moradores, apesar da distância, podem preservar uma identificação com o referido território. Posto que a sua própria trajetória está atravessada pela história daquele lugar.

Ademais, em vez de discutirem uma predominância de italianos ou negros no bairro, os depoentes apontaram os nordestinos como o maior grupo identitário atualmente. Esta constatação indica a importância de realizar um estudo mais aprofundado acerca da migração nordestina neste contexto, bem como o posicionamento dos nordestinos numa rede de disputas sociais.

Verifica-se ainda que a população negra e nordestina é majoritária nos cortiços e nos imóveis de baixo custo, carregados de referências pejorativas, muitas vezes alvos da desapropriação e revitalização, caso da Vila Itororó. Além disso, é importante salientar que tanto os colaboradores deste estudo, como a pesquisa de campo, apontaram para um número considerável de imigrantes africanos nos cortiços da região.

Por final, na Bela Vista, é nítido o conflito mediante o planejamento urbano de uma área de localização privilegiada, tensões atravessadas também pelo marcador racial. Onde 
espaços de referência da população negra são estigmatizados e marginalizados, caso da escola de Samba Vai-Vai, cujas ameaças de demolição não é fato recente. 


\section{Referências bibliográficas}

BORGES, Rosangela. Axé, madona Achiropta! Presença da cultura afro-brasileira nas celebrações da igreja de Nossa Senhora Achropita, em S. Paulo. São Paulo: Edições Pulsar, 2001.

CAMPOS, Andrelino de Oliveira. As questões étnico-raciais no contexto da segregação socioespacial na produção do espaço urbano brasileiro: Algumas considerações teórico metodológicas. In: Questões Urbanas e Racismo. Petrópolis: DP et Alii, 2012.

CALDEIRA, Teresa Pires do Rio. A política dos outros. O cotidiano dos moradores da periferia e o que pensam do poder e dos poderosos, São Paulo, Brasiliense, 1984.

CASTRO, Márcio Sampaio de Castro. Bexiga. Um Bairro Afro-Italiano: Comunicação, Cultura e Construção da Identidade Étnica. Dissertação de Mestrado em Comunicação. USP SP, 2006.

D’ALAMBERT, Clara Correia; FERNANDES, Paulo Cesar Gaioto. Bela Vista: a preservação e o desafio da renovação de um bairro paulistano. Revista do Arquivo Histórico de São Paulo, São Paulo, v. 204, p. 150-168, 2006.

ECOSTEGUY, Ana Carolina. Estudos Culturais: uma introdução. O que é, afinal, estudos culturais? .3. ed. Belo Horizonte: Autêntica Editora, 2006.

GUIMARÃES, Antônio Sérgio Alfredo. Racismo e Anti-racismo no Brasil. São Paulo, Editora 34, 1999.

IBGE. Censo Demográfico 2010. Dados Demográficos dos Distritos Pertencentes às Sub Prefeituras. Disponível em: <http://www.prefeitura.sp.gov.br/cidade/secretarias/sub prefeituras/subprefeituras/dadosdemgaficos/index.php?p=12758>. Acesso em: 26 jan. 2013.

HOFBAUER, Andreas. O Conceito de Raça e o Ideário do "Branqueamento" no Século XIX - Bases Ideológicas do Racismo Brasileiro. In: Teoria e Pesquisa 42 e 43, jul. 2003. 
LUCENA, Célia Toledo. Bairro do Bexiga: A Sobrevivência Cultural. São Paulo: Brasiliense. 1984.

MUNANGA, Kabengele; GOMES, Nilma Lino. Para entender o Negro no Brasil de Hoje: Histórias, Realidades, Problemas e Caminhos. Livro do Estudante. São Paulo: Ed. Global/Ação Educativa, 2004.

OLIVEIRA, Reinaldo José de. Segregação Urbana e Racial na Cidade de São Paulo: as periferias de Brasilândia, Cidade Tiradentes e Jardim Ângela. 2008. (Tese de Doutorado em Ciências Sociais). Departamento de Ciências Sociais, Pontifícia Universidade Católica de São Paulo.

PAIXÃO, Marcelo et. al. (Org.). Relatório Anual das Desigualdades Raciais no Brasil; 2009-2010. Rio de Janeiro: Garamond Universitária. 2010. Disponível em:< http://www.palmares.gov.br/wp-content/uploads/2011/09/desigualdades_raciais_20092010.pdf>. Acesso em 30 de jan. de 2013.

SÃO PAULO. Prefeitura Municipal. HABI - Superintendência de Habitação Popular. Cortiços: A Experiência de São Paulo, 2010. Disponível em: < $\underline{\text { http://www }}$ .habisp.inf.br/theke/documentos/publicacoes/corticos/index.html>. Acesso em: 25 jan. 2013.

SÃO PAULO. Prefeitura Municipal. Subprefeitura Cidade Tiradentes. Cidade Tiradentes: O bairro que mais parece uma cidade, s/d. Disponível em: < http://www.prefeitura.sp.gov.br/cidade/secretarias/subprefeituras/cidade_tiradentes/historico/i ndex.php?p=94>. Acesso em: 10.07. 2013.

SOARES, Reinaldo da Silva. O cotidiano de uma escola de samba paulistana: O caso do Vai-Vai. 1999. 229 f. Dissertação (Mestrado em Antropologia Social) - Faculdade de Filosofia e Ciências Humanas, Universidade de São Paulo, São Paulo, 2005. 
QUEIROZ, Maria Isaura Pereira. Relatos orais: do "indizível” ao "dizível”. In: VON SIMSON, Olga Moraes. (Org). Experimentos com história de vida (Itália-Brasil). São Paulo: Vértice, 1998, p.14-43.

ROLNIK, Raquel. Territórios Negros nas Cidades Brasileiras - Etnicidade e cidade em São Paulo e Rio de Janeiro. In: Revista de Estudos Afro-Asiáticos, Rio de Janeiro, Cadernos Cândido Mendes, nº $^{\circ}$, set. 1989.

SACCHETO, João. Bixiga: Pingos nos Is. São Paulo, Lemos Editorial, 2001.

SANTOS, Carlos José Ferreira dos. Nem tudo era italiano: São Paulo e pobreza 1890 1915. São Paulo: Anablume/ Fapesp, 2003.

SILVÉRIO, Valter Roberto. Ação Afirmativa e o combate ao racismo institucional no Brasil. In: Cadernos de Pesquisa, São Paulo, $\mathrm{n}^{\mathbf{0}}$ 117, nov. 2002. Disponível em: < http://www.scielo.br/pdf/cp/n117/15560.pdf >

; TRINIDAD, Cristina Teodoro. Há algo novo a se dizer sobre as relações raciais no Brasil contemporâneo? Educação e Sociedade. Campinas, v.33, n. 120, p.891-914, jul. - set. 2012. Disponível em: 〈http://www.cedes.unicamp.br>

\section{Reportagens}

BEVENUTI, Patrícia. Famílias são despejadas da Vila Itororó. São Paulo, Brasil de Fato. 20 mar. 2013. Disponível em: <http://www.brasildefato.com.br/node/12031>. Acesso em: 25 fev. 2013

VEIGA, Edson; BURGARELLI Rodrigo. Restauro da Vila Itororó começa a sair do Papel. Estadão, 28 mar. 2012. Disponível em: <http://blogs.estadao.com.br/edison-veiga/2012/03 /28/2290/>. Acesso em: 20 fev. 2013.

Vídeos 
COLETIVO MAPA XILOGRÁFICO. Moradia no Bixiga. São Paulo, 2009. Disponível em: $<$ http://mapaxilografico.blogspot.com.br/2009/07/acervo-de-documentarios.html >. Acesso em: 25 jan. 2013.

DUARTE, Neide; POLI, Maria Cristina. Memória em Pedaços: Bairro do Bixiga - São Paulo, 1997. Vídeo (VHS), 30 min., cor. Disponível em: < http://www.saopauloantiga.com.br/memoria-em-pedacos-bixiga/>. Acesso em 25/07/2012.

MANFRINI, André; et. al. Vila Itororó: Entre o Concreto e o Humano. São Paulo, 2011. Vídeo. Disponível em: < http://www.youtube.com/watch?v=qrUgYBFlyXo>. Acesso em: 20 fev. 2013.

\section{Discografia}

FILME, Geraldo. Tradição. Memória Eldorado: Geraldo Filme. Eldorado, São Paulo, 1980. CD. 